other two required surgical decompression with either an antegrade or retrograde ureteric irrigation. We would therefore advise that failure to respond to conservative management within 24 hours, or the development of hypertension, should lead to more direct attempts to relieve obstruction.

Finally we recommended that after recovery, all of these children should be investigated for the possibility of an underlying crystalluria.

1 Arneil GC. Twenty-nine children with sulphonamide haematuria. Lancet 1958;i:826-7.
2 Barratt TM. Acute renal failure. In: Holliday M, Barratt TM, Vernier R, eds. Pediatric nephrology. 2nd Ed. Baltimore: Williams and Wilkins, 1987:766-72.

3 Kjellstrand CM, Campbell DC, Von Hartitzsch B, et al. Hyperuricaemic acute renal failure. Arch Intern Med 1974; 133:349-59.

4 Coe FL, Favus MJ. Nephrolithiasis. In: Braunwald E, Isselbacher KJ, Petersdorf EG, et al, eds. Harrison's principles of intermal medicine. 11th Ed. New York: McGraw Hill, 1987:1211-5.

5 Curatola G, Mazzitelli R, Monzani G, et al. The value of ultrasound as a screening procedure for urological disorders in renal failure. $\mathcal{F}$ Urol 1983;130:8-10.

6 Erwin BC, Carroll BA, Sommer FG. Renal colic: the role of ultrasound in initial evaluation. Radiology 1984;152: 147-50.

\title{
Pain and measles, mumps, and rubella vaccination
}

\author{
Ronan Lyons, Fenton Howell
}

\begin{abstract}
Seventy seven children (mean age $\mathbf{4 4 . 2}$ months) were entered in a randomised double blind study to find out if two commonly used measles, mumps, and rubella (MMR) vaccines (Pluserix and MMR II) caused pain on injection. Pain was judged by the amount of crying. Infants given MMR II were 2.31 times more likely to cry than those given Pluserix.
\end{abstract}

A vaccination programme to eliminate measles, mumps, and rubella (MMR) from the British Isles was introduced in October 1988. Two vaccines, Pluserix (Smith Kline French) and MMR II (Wellcome), have been used extensively in the campaign and they have comparable immunogenicity and reactogenicity. ${ }^{1}$ Since the start of the campaign some family doctors in Ireland reported that the MMR II vaccine caused more distress to children than the Pluserix vaccine. Similar reports came from the United Kingdom. ${ }^{2}$ Although the data sheet for MMR II states that the vaccine may cause burning or stinging at the injection site for a short time because the reconstituted vaccine is slightly acid (pH 6.2-6.6), we know of no published evidence to suggest that immediate pain at the injection site is a problem. ${ }^{3}$ We decided to investigate the matter further.

\section{Subjects and methods}

Eastern Health Board, Community Care Area 7, Aras Daimhin, Croke Park, Jones's Road, Dublin 3, Republic of Ireland Ronan Lyons Fenton Howell

Correspondence to: Dr Howell.

Accepted 16 October 1990

(ArchDisChild 1991;66:346-7)
An inner city coeducational preschool population from a socially deprived area with a poor uptake of the MMR vaccine was chosen for the study. All children who had not been vaccinated were invited to attend for vaccination on one of two consecutive days. All children being vaccinated were accompanied by someone they knew well. Each child received $0.5 \mathrm{ml}$ of vaccine subcutaneously through a 25 gauge needle into the deltoid region of the left arm. All vaccines were given by a single experienced doctor (RL). Crying after the injection was used as a measure of pain, and was assessed by the other doctor (FH). A randomised double blind study design was used, in which each vaccine was randomly selected from a previously coded lot and neither the doctors nor the recipients were aware of which vaccine had been used until the trial had been completed. Vaccinated children were kept separate from unvaccinated ones to avoid 'contamination'. Data were analysed by $\chi^{2}$ test, Fisher's exact test, or Student's $t$ test.

\section{Results}

Of the 97 children presenting, 20 cried before vaccination. Of the remaining 77 (37 boys and 40 girls), 37 (mean (SD) age $43 \cdot 4(11 \cdot 1)$ months) received Pluserix and 40 (mean (SD) age $45 \cdot 2$ (10.7) months) received MMR II. There were no differences in the age between the groups or sex of the children.

The table shows the number that cried after vaccination. Children who received MMR II were 2.31 times more likely to cry than those who received Pluserix ( $95 \%$ confidence interval $1 \cdot 16$ to $4 \cdot 60$ ). Neither age nor sex were significantly associated with crying. Of the 28 children who cried after vaccination, none cried for longer than a minute.

\section{Discussion}

The results of this study suggest that pain is a real and unnecessary side effect of some MMR vaccines. Though we recognise that there are many difficulties in measuring pain, we feel that crying after vaccination is a reasonable measure

Incidence of crying after the two vaccines

\begin{tabular}{lclc}
\hline & $\begin{array}{l}\text { No who } \\
\text { cried }\end{array}$ & $\begin{array}{l}\text { No who } \\
\text { did not cry }\end{array}$ & Total \\
\hline $\begin{array}{l}\text { Pluserix } \\
\text { MMR II }\end{array}$ & 8 & 29 & 37 \\
\hline Total & 20 & 20 & 40 \\
\hline
\end{tabular}


in this instance, as we were able to control for many other factors that could be associated with crying (age, sex, social class, familiar location, presence of someone that they knew well, avoidance of 'contamination', skilled operator, and method). We are therefore satisfied that the difference in response to the two vaccines was the result of the difference between the two vaccines and not of some extraneous factor, and that the most probable cause for this was the acidity of the MMR II vaccine.

Although the difference is significant, one must keep in mind the clinical relevance of these findings. It could be argued that even those who did cry cried for no more than a minute and so the clinical relevance may not be obvious. However, this argument fails to take account of the fact that if one is given a free choice about whether to feel a 'little' pain or no pain at all, most would prefer to have no pain. In addition, those who give vaccines to children will be well aware of the effects of a crying baby on the accompanying parent or minder, as well as on other children who may be waiting to undergo a similar experience. Hence we feel that the findings are of clinical relevance.

This study was primarily carried out among children who had defaulted from the vaccination programme. The mean age of those studied is higher than that of the population of children targeted for vaccination. One cannot necessarily extrapolate the findings of such a study to a younger age group, given that so little is known about pain in babies and toddlers and the difficulties of measuring it.

1 Vesikari T, Ala-Laurila E, Heikkinen A, Terho A, D'Hondt E, Andre F. Clinical trial of a new trivalent measlesmumps-rubella vaccine in young children. Am $\mathcal{J}$ Dis Child 1984;138:843-7.

2 Rowbotham P. Pain with MMR vaccine. Pharmaceutical fournal 1988;241:797.

3 Peltola $\mathrm{H}$, Heinonen $\mathrm{O}$. Frequency of true adverse reactions to measles-mumps-rubella vaccine. Lancet 1986;i:939-42.

\section{Tuberculosis in a contact}

\section{Department of Paediatrics, \\ National Heart and Lung Institute and Brompton Hospital, London \\ Andrew Bush \\ J O Warner \\ Correspondence to: Dr Andrew Bush Department of Paediatric Respiratory Medicine, Royal Brompton and National Heart Hospital, Fulham Road, London SW3 6HP.}

Accepted 19 November 1990 (Arch DisChild 1991;66:347-8)
Andrew Bush, J O Warner

\begin{abstract}
A 12 year old girl developed a large tuberculous pleural effusion. She was a contact of an adult with pulmonary tuberculosis who was positive on smear testing, and she had been managed in accordance with current British Thoracic Society recommendations.
\end{abstract}

The British Thoracic Society have recently published guidelines on the management of contacts of pulmonary tuberculosis. ${ }^{1}$ We recently treated a child who developed tuberculosis from a known index case, despite being treated apparently in accord with these guidelines.

\section{Case report}

A 12 year old Asian girl was referred for investigation of a pleural effusion. She had been well until two days previously, when she became breathless during a physical education lesson, and was sent to the school doctor. A chest infection was diagnosed, but a chest radiograph showed a complete whiteout of the left hemithorax, and she was referred to hospital. On direct questioning she admitted to a two week history of a dry cough. She was an adopted child, and her adoptive mother (a doctor) was confident that she had had BCG vaccination at birth. Six months previously she had been seen in a chest clinic because the au pair girl, who had been with the family for two months, was found to have pulmonary tuberculosis that was positive on smear testing. Six weeks after the last contact with the index case the Heaf test was grade two positive, with a normal chest radiograph, and therefore no action was taken and no follow up appointment given. On examination her temperature was $37.6^{\circ} \mathrm{C}$ and she looked unwell. The only other physical signs were those of a large left pleural effusion. There was no scar of a previous BCG vaccination visible.

Investigations showed her haemoglobin concentration to be $124 \mathrm{~g} / 1$, white cell count $5.7 \times 10^{9} / 1$, platelet count $324 \times 10^{9} / 1$, and erythrocyte sedimentation rate $38 \mathrm{~mm}$ in the first hour. She had normal urea and electrolyte, calcium, and phosphate concentrations and normal results on liver function tests. A Mantoux with $0.1 \mathrm{ml}$ of 1 in 10000 old tuberculin intradermally showed $15 \mathrm{~mm}$ of induration. A chest drain was inserted, and a total of 2.5 litres of straw coloured fluid was drained from the left chest. The pleural biopsy specimen showed necrotising granulomatous inflammation with Langerhans giant cells. Bronchoscopy was unremarkable. Pleural fluid and bronchial washings were culture negative for tuberculosis. She was started on pyrazinamide, rifampicin, and ethambutol because the organism in the index case was resistant to isoniazid, and she made a rapid recovery. Her mother subsequently rechecked the adoption papers, and found that the girl had not after all had a BCG vaccination.

\section{Discussion}

The development of a tuberculous pleural effusion in this child represents a failure of follow up. At the initial screening, there was a 